DOI: 10.12731/2227-930X-2021-11-4-83-91

УДК 004.94

\title{
ИССЛЕДОВАНИЕ ВОЗМОЖНОСТЕЙ РАЗВИТИЯ ТРАНСПОРТНОЙ СИСТЕМЫ В РЕГИОНЕ
}

\author{
Львович Я.Е., Преображенский А.П., \\ Преображенский Ю.П.
}

В статье рассматривается задача, связанная с изучением характеристик транспортной системы в регионе. Показаны возможности использования комплексного подхода, учитывающего обработку пространственно-временной информащии.

Ключевые слова: система перевозок; модель; предприятие; управление

\section{THE RESEARCH OF THE POSSIBILITIES OF THE TRANSPORTATION SYSTEM DEVELOPMENT IN THE REGION}

\section{Lvovich Ya.E., Preobrazhenskiy A.P., Preobrazhenskiy Yu.P.}

The paper deals with the problem associated with the study of the characteristics of the transport system in the region. Possibilities of using an integrated approach that takes into account spatio-temporal information.

Ключевые слова: transportation system; model; enterprise; control

\section{Введение}

За счет совершенствования структуры управления существуют возможности для того, чтобы осуществлять решение по проблемам, связанным с рациональным применением различных ресурсов и компонентов в транспортной системе. 
Существуют задачи, которые возникают на практике, в которых требуется создавать мониторинга регионов по работе транспортной системы. В качестве одного из перспективных способов, позволяющего осуществлять повышение эффективности управления транспортными системами $[1,2]$ можно считать создание мониторинга с привлечением геоинформационных технологий.

Цель работы состоит в демонстрации комплексного подхода, который может быть использован для анализа транспортных систем в регионе.

\section{Модель транспортной системы}

Решение задач, позволяющих вести оценку динамики и проведения прогнозов, основывается на том, что будут применяться внутри единой среды геоинформационные системы (ГИС), а также математических методики прогнозирования. Тогда происходит поддержка принятия управленческих решений [3].

Основа интеграции вытекает из применения географической информации в ГИС, чтобы вести обработку по пространственно временным данным, Эта обработка внутри ГИС является комплексной. От сбора информации до ее хранения ведется поддержка соответствующих процессов [4].

В ГИС входят разные технологии сбора информации. За счет различных способов вывода данных можно оперативным образом получать атрибутивные данные, которые строятся при помощи табличных или графовых форм.

Возможность управления транспортными системами основывается на прогнозировании ситуаций. При этом требуются прогностические оценки по изменению показателей.

В этой связи в качестве важного этапа в исследовании можно считать применение краткосрочного прогнозирования. Методики адаптивного прогнозирования характеризуются весьма широкими возможностями [5].

Базируются они на использовании моделей экспоненциального сглаживания. В чем состоит ключевая идея? Происходит процесс 
сглаживания временного ряд на основе взвешенной скользящей средней.

Распределение внутри нее весов происходит в рамках экспоненциального закона. Значения в динамическом ряде, которые будут находиться к концу интервала сглаживания, будут описываться при помощи отмеченной нами взвешенной скользящей средней.

Способ картографического анализа позволяет решать множество задач. Например, по определенным явлениям в транспортных системах $[6,7]$ можно продемонстрировать их пространственное положение.

Кроме того, такие явления будут демонстрироваться с точки зрения их взаимосвязей, за счет раскрытия их смысла и значений. Это вытекает из того, какие цели в транспортных исследованиях.

Можно увидеть взаимосвязи среди характеристик транспортных компонент и соответствующими географическими факторами на анализируемой территории при помощи специальной карты.

Картографический анализ комбинируется со статистическим моделированием. Эту задачу эффективно можно решать с привлечением геоинформационных систем (ГИС). С чем это связано?

Они рассматриваются в виде современных средств. Они позволяют интегрировать статистический анализ, математическое моделирование, а также средства управления базами данных. По пространственно-организационным данным, как результат, можно осуществлять процессы исследований $[8,9]$.

Новые виды зависимостей могут быть установлены за счет того, что привлекаются ГИС, среди сборов транспортных, экологических, энергетических и географических данных. Они будут подвергаться процедурам пространственного анализа.

Для пользователей предоставляются возможности за счет применения ГИС по тому, чтобы вести оптимизацию процессов управления, а также выбора стратегий, когда формируется плана мероприятий в транспортных [10] системах (рис. 1).

Программное обеспечение, периферийные устройства, а также объемы обрабатываемой информации накладывают соответствующие требования по составу аппаратного комплекса ГИС. 
Требуется реализовывать многовариантный подход при моделировании транспортной информации. Тогда корректным образом используются мониторинговые подходы, чтобы давать оценки и прогнозы по транспортным характеристикам внутри региона при учете пространственных аспектов.

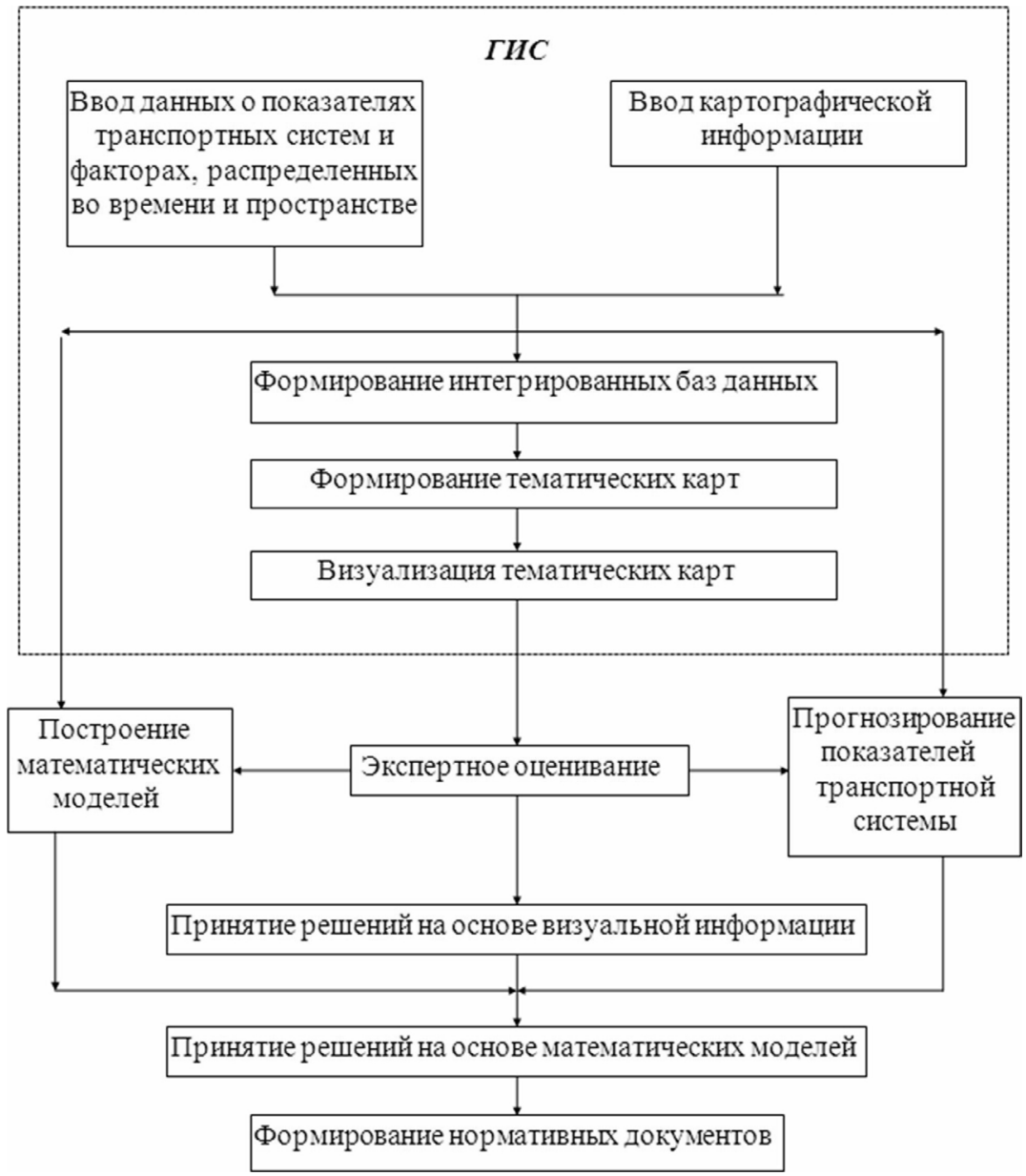

Рис. 1. Иллюстрация структурной схемы, позволяющей интегрировать процедуры в ГИС, связанных с моделированием, прогнозированием и принятием решений 
Длина исследуемого ряда, проявление определенных сезонных эффектов оказывает влияние на то, какой будет выбран метод прогнозирования.

Экстраполяция временных рядов по тренду можно применять, когда получаются прогнозные оценки на основе способов прямого прогнозирования.

Мы предлагаем применять модель экспоненциального сглаживания с тем, чтобы формировать краткосрочный прогноз. Указанный подход может быть рассмотрен в ходе реализации прогнозирования по нестационарным временным рядам. Они характеризуются случайными изменениями по уровню и углу наклона. Тогда говорится о том, что используется метод Брауна.

Полином, имеющий невысокую степень, позволяет сформировать основную модель ряда. При этом будет медленное изменение со временем в нем коэффициентов:

$$
y(t)=\alpha x(t)+(1-\alpha) y(t-1),
$$

В указанном выражении $\alpha-$ рассматривается в виде параметра сглаживания. В тренде его тип будет оказывать влияние на начальное значение:

когда тренд будет экспоненциальным

$$
s(0)=x(2) / x(1) ; y(0)=x(1) / \sqrt{s(0)},
$$

если тренд будет линейным

$$
s(0)=(x(n)-x(1)) /(n-1) ; y(0)=x(1)-s(0) / 2 .
$$

Вычислительный процесс устроен как адаптивная процедура, в которой коэффициенты полинома пересчитываются по старым коэффициентам и новым данным. Процесс вычислений подчиняется таким параметрам: порядку апроксимирующего полинома и параметру сглаживания. В чем состоит особенность? Чем параметр сглаживания будет ближе к единице, тем влияние больше по последним наблюдениям.

С привлечением комбинации ГИС-технологий, а также и моделей, позволяющих осуществлять краткосрочное прогнозирование, на базе статистических данных нам удалось получить прогностические модели. Дана их иллюстрация в табл. 1. 
Таблица 1.

Демонстрация параметров математических моделей, позволяющих прогнозировать показатели работы одного из предприятий в районе г. Воронежа

\begin{tabular}{|l|l|l|l|l|c|}
\hline \multicolumn{2}{|c|}{} & Тренд & $y(0)$ & $x(0)$ & $\alpha$ \\
\hline \multirow{3}{*}{ Ремонт автотранспорта } & Отремонтировано & Эксп. & 1127 & 1 & 0,358 \\
\cline { 2 - 6 } & Рабочих дней & Эксп. & 321 & 1 & 0,552 \\
\cline { 2 - 6 } & Ср.число раб. дней & Эксп. & 295 & 2 & 0,677 \\
\hline \multirow{3}{*}{ Ремонт легковых автомобилей } & Отремонтировано & Лин. & 753 & 5 & 0,004 \\
\cline { 2 - 6 } & Рабочих дней & Лин. & 312 & 3 & 0,180 \\
\cline { 2 - 6 } & Ср.число раб. дней & Лин. & 301 & 4 & 1 \\
\hline
\end{tabular}

\section{Выводы}

В работе рассмотрена задача определения характеристик транспортной системы в регионе. Показаны соответствующие составляющие алгоритмического обеспечения, а также результаты моделирования.

Авторы заявляют об отсутствии конфликта интересов.

Исследование не имело спонсорской поддержки.

\section{Список литературы}

1. Преображенский Ю.П. Информационные технологии, используемые в сфере менеджмента // Вестник Воронежского института высоких технологий. 2018. № 2 (25). С. 43-46.

2. Жилина А.А., Кострова В.Н., Преображенский Ю.П. Разработка методики постановки задачи выбора управленческого решения на основе оптимизационного подхода // Моделирование, оптимизация и информационные технологии. 2018. Т. 6, № 1 (20). C. 243-253.

3. Преображенский Ю.П., Мирошник Д.Н. Анализ методов нечеткого поиска // Вестник Воронежского института высоких технологий. 2018. № 4 (27). С. 82-84.

4. Преображенский Ю.П., Коновалов В.М. О методах создания рекомендательных систем // Вестник Воронежского института высоких технологий. 2019. № 4 (31). С. 75-79. 
5. Берман Н.Д., Белов А.М. Общественный транспорт и инновации // International Journal of Advanced Studies. 2019. T. 9, № 2. С. 7-13.

6. Шакиров А.А., Зарипова Р.С. Особенности моделирования логистических систем // International Journal of Advanced Studies. 2019. T. 9, № 4. C. 27-31.

7. Сапожникова С.М. Корпоративное управление в железнодорожном транспорте // International Journal of Advanced Studies. 2019. T. 9. № 4. С. $19-42$.

8. Грошев А.Г., Фролов В.Н., Федорков Е.Д. Построение онтологических моделей систем автоматизированного проектирования // Вестник Воронежского института высоких технологий. 2020. № 4 (35). C. 52-56.

9. Львович Э.М., Холодков А.М. Проблемы передачи информации в автоматизированных системах управления // Вестник Воронежского института высоких технологий. 2020. № 3 (34). С. 30-33.

10. Львович Я.Е., Львович И.Я., Львович Э.М. Проблемы обработки цифровых сигналов в системах передачи информации // Вестник Воронежского института высоких технологий. 2020. № 3 (34). C. 27-29.

\section{References}

1. Preobrazhenskij YU.P. Vestnik Voronezhskogo instituta vysokih tekhnologij, 2018, no. 2 (25), pp. 43-46.

2. Zhilina A.A., Kostrova V.N., Preobrazhenskij YU.P. Modelirovanie, optimizaciya i informacionnye tekhnologii, 2018, vol. 6, no. 1 (20), pp. 243-253.

3. Preobrazhenskij YU.P., Miroshnik D.N. Vestnik Voronezhskogo instituta vysokih tekhnologij, 2018, no. 4 (27), pp. 82-84.

4. Preobrazhenskij YU.P., Konovalov V.M. Vestnik Voronezhskogo instituta vysokih tekhnologij, 2019, no. 4 (31), pp. 75-79.

5. Berman N.D., Belov A.M. International Journal of Advanced Studies, 2019, vol. 9, no. 2, pp. 7-13.

6. Shakirov A.A., Zaripova R.S. International Journal of Advanced Studies, 2019, vol. 9, no. 4, pp. 27-31. 
7. Sapozhnikova S.M. International Journal of Advanced Studies, 2019, vol. 9, no. 4, pp. 19-42.

8. Groshev A.G., Frolov V.N., Fedorkov E.D. Vestnik Voronezhskogo instituta vysokih tekhnologij, 2020, no. 4 (35), pp. 52-56.

9. L'vovich E.M., Holodkov A.M. Vestnik Voronezhskogo instituta vysokih tekhnologij, 2020, no. 3 (34), pp. 30-33.

10.L'vovich YA.E., L'vovich I.YA., L'vovich E.M. Vestnik Voronezhskogo instituta vysokih tekhnologij, 2020, no. 3 (34), pp. 27-29.

\section{ДАННЫЕ ОБ АВТОРАХ}

Львович Яков Евсеевич, профессор, доктор технических наук, профессор

Федеральное государственное образовательное учреждение высшего образования Воронежский государственный технический университет

ул. 20 лет Октября, 84, г. Воронеж, 394006, Российская Федерачия

Komkovvivt@yandex.ru

Преображенский Андрей Петрович, профессор, доктор технических наук, доцент Автономная некоммерческая образовательная организаџия высшего образования Воронежский институт высоких технологий

ул. Ленина, 73а, г. Воронеж, 394043, Российская Федераџия Komkovvivt@yandex.ru

Преображенский Юрий Петрович, профессор, кандидат технических наук, доцент Автономная некоммерческая образовательная организачия высшего образования Воронежский институт высоких технологий

ул. Ленина, 73а, г. Воронеж, 394043, Российская Федерация Komkovvivt@yandex.ru 


\section{DATA ABOUT THE AUTHORS}

Yakov Ye. Lvovich, Doctor of Technical Sciences, Professor

Voronezh State Technical University

84, 20 years of October Str., Voronezh, 394006, Russian Federation

Komkovvivt@yandex.ru

ORCID: 0000-0002-7051-3763

Andrey P. Preobrazhenskiy, Professor, Doctor of Technical Sciences, Associate Professor

Voronezh Institute of High Technologies

73a, Lenin Str., 73a, Voronezh, 394043, Russian Federation

Komkovvivt@yandex.ru

ORCID: 0000-0002-6911-8053

Yuriy P. Preobrazhenskiy, Professor, Candidate of Technical Sciences, Associate Professor Voronezh Institute of High Technologies

73a, Lenin Str., 73a, Voronezh, 394043, Russian Federation Komkovvivt@yandex.ru 